\title{
Reduced fructosamine-3-kinase activity and its mRNA in human distal colorectal carcinoma
}

\author{
M. Notarnicola $\cdot$ Maria G. Caruso • \\ V. Tutino $\cdot$ V. Guerra $\cdot$ S. Frisullo $\cdot$ \\ D. F. Altomare · G. Misciagna
}

Received: 30 September 2009/Accepted: 21 December 2009/Published online: 3 February 2010

(C) Springer-Verlag 2010

\begin{abstract}
Fructosamine-3-Kinase (FN3K) is an enzyme phosphorilating fructoselysine (FL) residues on glycated proteins, resulting in the production of protein-bound FL-3phosphate. The pathological role of the non-enzymatic modification of proteins by reducing sugars has become increasingly evident in various types of disorders, including the cancer. In this study, our aim was to study FN3K enzyme activity, as well as its mRNA in human colorectal cancer (CRC). Thirty consecutive CRC patients undergoing surgery of the colon were enrolled in the study. FN3K enzymatic activity and gene expression were analyzed using a radiometric assay and quantitative RT-PCR, respectively. FN3K is a functionally active enzyme in human colon tissue, without significant differences between normal mucosa and cancer. The mean level of FN3K mRNA was significantly lower in cancer than in the corresponding normal colorectal mucosa The colorectal tumors located on the left side showed lower levels of both enzymatic activity and mRNA FN3K than tumors located
\end{abstract}

M. Notarnicola and M.G. Caruso have equally contributed to this work.

M. Notarnicola $\cdot$ M. G. Caruso $(\bowtie) \cdot$ V. Tutino

Laboratory of Biochemistry,

National Institute for Digestive Diseases, Via della Resistenza,

70013 Castellana Grotte, Bari, Italy

e-mail: gabriella.caruso@irccsdebellis.it

V. Guerra $\cdot$ S. Frisullo $\cdot$ G. Misciagna $(\bowtie)$

Laboratory of Epidemiology and Biostatistic,

National Institute for Digestive Diseases, IRCCS “S. de Bellis",

Via Turi, 27, 70013 Castellana Grotte, Bari, Italy

e-mail: gmisciag@libero.it

D. F. Altomare

Division of Surgery, DETO, University of Bari, Bari, Italy in the right side of colon. This paper is the first studying FN3K enzyme activity in human CRC, showing a significant relationship between enzymatic activity, its mRNA and tumor side.

Keywords Colorectal cancer .

Fructosamine-3-kinase activity · Gene expression .

Glycation

\section{Introduction}

Protein glycation is a spontaneous reaction of reducing sugars with amino groups of proteins. In this reaction, the $\varepsilon$-amino group of lysine condenses with the carbonyl of a sugar to form a Schiff's base, which then slowly undergoes an Amadori rearrangement to become a ketoamine or, if reacting sugar is glucose, fructosamines $[3,9,26]$. The fate of fructosamines is to continue to react slowly until they become "advanced glycation end products" (AGEs), which are thought to play a role in the pathophysiology of several human disorders, most particularly diabetes $[1,5]$.

The non-enzymatic reaction of protein amino groups with glucose and other reducing sugars has long been considered irreversible $[8,25]$. However, recent evidence indicates that fructosamines can be repaired by Fructosamine-3-Kinase (FN3K), which phosphorilates fructoselysine (FL) residues on glycated proteins, resulting in the production of protein-bound FL-3-phosphate (FL3P) [16]. The physiological occurrence of deglycation has been proven by showing that protein-bound fructosamines are present at high concentrations in tissues and erythrocytes of FN3K-deficient mice respect to the control mice [4].

The pathological role of the non-enzymatic modification of proteins by reducing sugars, a process that is known as 
the "Maillard reaction", has become increasingly evident in various types of disorders $[4,9,10]$. Glycation is part of the broader concept of the Maillard reaction, in which all sorts of reactive carbonyl compounds inflict cellular and tissue damage during aging and in age-related disease [17]. Diseases of "carbonyl stress" include among others, diabetes and end-stage renal disease, in which levels of AGEs (advanced glycation end products) reach staggering concentrations. The role of AGEs in the pathophysiology of various chronic and age-related diseases has been scientifically well accepted $[22,24]$. Recent studies show that in addition to those endogenously formed, diet constitutes an important exogenous source of AGEs [20, 28]. Food-derived AGEs are found to play an important role in the pathogenesis of the AGE-related disorders, so that the restriction of foodderived AGEs or the inhibition of absorption of dietary AGEs may be a novel target for therapeutic intervention in patients with diabetes or chronic renal failure [28].

Differences in the efficiency with which individual patients detoxify glycated proteins may explain individual differences in susceptibility to complications of hyperglycemia [22].

Recent evidence indicates that malignant cell transformation may be considered a disease of "carbonyl stress". The risk of colorectal adenoma has been related to high levels of serum fructosamine [15].

Previously, we evaluated FN3K gene expression in colorectal cancer (CRC) patients, showing that the FN3K gene expression was significantly lower in colon cancer tissue than in the corresponding normal surrounding mucosa, and that FN3K gene was particularly down-regulated in the tumors located on the left side of the colon. These findings suggest that cancer cells have lost a protective enzymatic system or that it is at low levels [6].

There is the possibility that an appreciable difference in FN3K gene expression produces variation in the levels of enzymatic activity between normal tissue and cancer or between right and left side of colon in CRC patients. In order to verify this hypothesis, in a new group of CRC patients, we have evaluated FN3K activity levels as well as the expression of its mRNA in normal colorectal mucosa and cancer tissues.

\section{Patients and methods}

Patients

Thirty consecutive CRC patients (14 men and 16 women, mean age $64.8 \pm 11.2$ years) undergoing surgery of the colon were enrolled in the study. Colorectal mucosa and cancer were obtained from each of them according to a standardized procedure. At once after removal, samples of mucosa were taken from macroscopically normal areas of colon at $10 \mathrm{~cm}$ from neoplastic lesion. Specimens were taken within $1 \mathrm{~h}$ after the surgical procedure and stored at $-80^{\circ} \mathrm{C}$ until assayed. All the patients gave informed consent to participate in the study.

The laboratory analyses were performed blindly with respect to the clinical characteristics and histopathologic features of the samples.

\section{FN3K activity assay}

Fructosamine-3-Kinase (FN3K) enzymatic activity was measured in normal colorectal mucosa and cancer. The tissue samples were left in $500 \mu \mathrm{l}$ of homogenization buffer $10 \mathrm{mM}$ Tris-HCl (pH 7.8), $1 \mathrm{mM}$ DTT, $1 \mu \mathrm{g} / \mathrm{ml}$ Leupeptin and centrifuged for $10 \mathrm{~min}$ at $4^{\circ} \mathrm{C}$ at $10000 \mathrm{rpm}$. Sample protein content was determined using Lowry's method. An aliquot of supernatant $(50 \mu \mathrm{l})$ was incubated with $100 \mu$ of reaction mix [ $5 \mathrm{mM}$ Glucose, $10 \mathrm{mM}$ Tris$\mathrm{HCl}$ (pH 7.8), $1 \mathrm{mM}$ DTT, $1 \mu \mathrm{g} / \mathrm{ml}$ Leupeptin and $2 \mathrm{mM}$ D-[1- $\left.{ }^{14} \mathrm{C}\right]$-Glucose $(49.5 \mathrm{mCi} / \mathrm{mmol}$, PerkinElmer Life and Analytical Sciences)] for $40 \mathrm{~min}$ at $37^{\circ} \mathrm{C}$. Subsequently, $30 \mu \mathrm{l}$ aliquots of the medium were spotted on cationexchange papers (P81 Whatman), which were washed three times with ice-cold $75 \mathrm{mM} \mathrm{H}_{3} \mathrm{PO}_{4}$ and then once with alcohol and once with acetone. After drying, the papers were counted for radioactivity in the presence of scintillant. FN3K activity was expressed as picomoles of incorporated $\mathrm{D}-\left[1-{ }^{14} \mathrm{C}\right]$-Glucose per minute per milligram of total protein (pmol $\mathrm{min}^{-1} \mathrm{mg}^{-1}$ protein).

The enzyme activity assay was validated on all studied samples in the presence of FN3K inhibitor (1-deoxy-1morpholino-fructose, DMF). The use of $25 \mathrm{mM}$ of DMF for each sample determinates a reduction in total radioactivity of $80 \%$. Then, the non-specific radioactivity due to amine compounds derived from other metabolic processes was negligible. In all the experiments, enzyme assays were carried out in duplicate. The coefficient percentages of intra-and inter-assay variation were 3 and $4 \%$, respectively.

FN3K gene expression analysis

Fructosamine-3-Kinase mRNA expression was determined using RT-PCR as described previously [6]. Briefly, total RNA from normal colorectal mucosa and cancer was isolated with TRI-Reagent (Mol. Res. Centre Inc. Cincinnati, O, USA), following the manufacturer's instruction. About $2 \mu \mathrm{g}$ extracted RNA were used for the reverse transcription reaction using antisense primer (FN3K sense $5^{\prime}$-CAA CCA GAA GCT CAG GGA GAA- $3^{\prime}, F N 3 K$ antisense $5^{\prime}$-GCT CAG CAC CCT CAC CTC TT- ${ }^{\prime}$, $\beta$-actin sense $5^{\prime}$-AAA GAC CTG TAC GCC AAC ACA GTG CTG TCT GG-3', $\beta$-actin antisense 5'-CGT CAT ACT CCT GCT TGC T 
GAT CCA CAT CTG C-3') for analyses of the FN3K and the $\beta$-actin gene. Human $\beta$-actin gene was utilized as an internal control, chosen as a reference gene because it is a housekeeping gene. Then, cDNAs were used for RT-PCR analysis, and the PCR products were quantified by external calibration curves, one for each tested gene, obtained with serial dilutions of known copy number of molecules $\left(10^{2}-\right.$ $10^{7}$ molecules). All expression data were normalized by dividing the target amount by the amount of $\beta$-actin used as internal control for each sample. The specificity of the PCR product was confirmed by gel electrophoresis.

\section{Statistical analysis}

The differences in FN3K activity and mRNA levels between normal mucosa and neoplastic tissue were analyzed by paired Student $t$ test.

The unpaired Student $t$ test was used in order to analyze the differences in FN3K activity and gene expression in relation to tumor site.

\section{Results}

The clinical and histopathologic features of all patients are shown in Table 1. All participants to the study were normoglycaemic subjects. At histology, all tumors were shown to be adenocarcinomas. They were classified according to their grade of histologic differentiation and tumor stage.

Table 1 Clinico-histopathologic features of colorectal cancer patients

\begin{tabular}{lc}
\hline & Cases $(n=30)$ \\
\hline Age (mean \pm SD) & $64.8 \pm 11.2$ \\
Sex & 14 \\
Men & 16 \\
Women & \\
Tumor side & \\
Right & 8 \\
Left & 22 \\
Tumor stage & \\
Stage I & 7 \\
Stage II & 6 \\
Stage III & 13 \\
Stage IV & 4 \\
Histologic grading & \\
Well differentiated (G1) & 6 \\
Moderately differentiated (G2) & 19 \\
Poorly differentiated (G3) & 5
\end{tabular}

${ }^{a}$ Right side: hepatic flexure, cecum and ascending colon; left side: descending colon, sigmoid and rectum

${ }^{\mathrm{b}}$ Clinical staging performed using UICC system
Fructosamine-3-Kinase activity and its mRNA were detectable in all samples. FN3K is a functionally active enzyme in human colon tissue, without significant differences between normal mucosa and cancer (20.2 \pm 2.6 vs. $22.4 \pm 2.4 \mathrm{pmol} \mathrm{min}^{-1} \mathrm{mg}^{-1}$ protein, mean value $\pm \mathrm{SE}$, $P>0.05$, paired $t$ test; Fig. 1a). According to our previous study [16], the mean level of FN3K mRNA was significantly lower in cancer than in the corresponding normal colorectal mucosa, being $0.44 \pm 0.08$ versus $0.74 \pm 0.15$ (mean values $\pm \mathrm{SE}$ ), respectively, expressed as number of mRNA FN3K molecules/number of mRNA $\beta$-actin molecules (paired $t$ test, $P=0.03$; Fig. $1 \mathrm{~b}$ ).

We have found significant differences in FN3K enzymatic activity and its gene expression levels between colon tumors located on the left and right side. The CRC tumors located on the left side showed lower levels of both enzymatic activity and FN3K mRNA than CRC tumors located in the right side $\left(19.4 \pm 2.5\right.$ vs. $31.6 \pm 4.8 \mathrm{pmol} \mathrm{min}^{-1} \mathrm{mg}^{-1}$ protein, mean values $\pm \mathrm{SE}, \quad P=0.02$, unpaired $t$ test, and $0.19 \pm 0.05$ vs. $0.68 \pm 0.02 \mathrm{n}^{\circ}$ molecules mRNA FN3K $/ \mathrm{n}^{\circ}$ molecules mRNA $\beta$-actin, mean values $\pm \mathrm{SE}, P=0.007$,
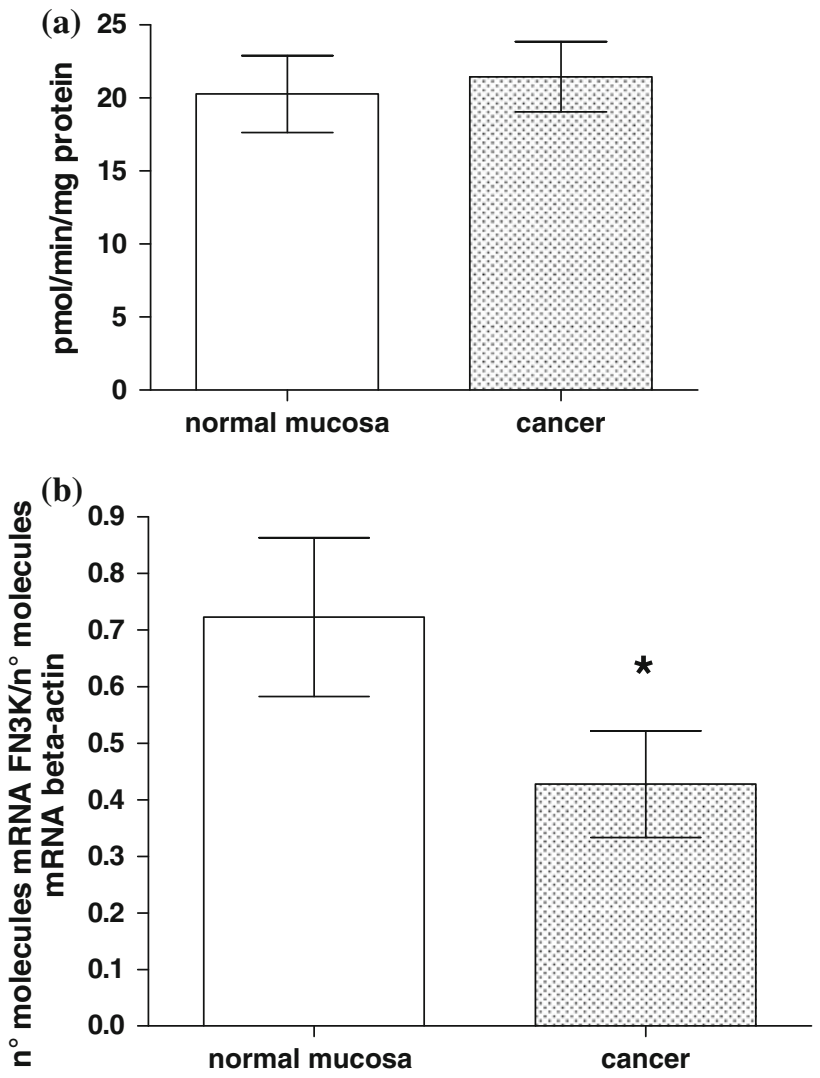

Fig. 1 FN3K activity (panel $a$ ) and mRNA (panel $b$ ) levels in colorectal normal mucosa and cancer $(20.2 \pm 2.6$ vs. $22.4 \pm 2.4 \mathrm{pmol} \mathrm{min}^{-1} \mathrm{mg}^{-1}$ protein, mean value $\pm \mathrm{SE}, P>0.05$, paired $t$ test and $0.74 \pm 0.15$ vs. $0.44 \pm 0.08$, mean value $\pm \mathrm{SE}$, expressed as $\mathrm{n}^{\circ}$ molecules mRNA $\mathrm{FN} 3 \mathrm{~K} / \mathrm{n}^{\circ}$ molecules mRNA $\beta$-actin, $P=0.03$, paired $t$ test, respectively) 

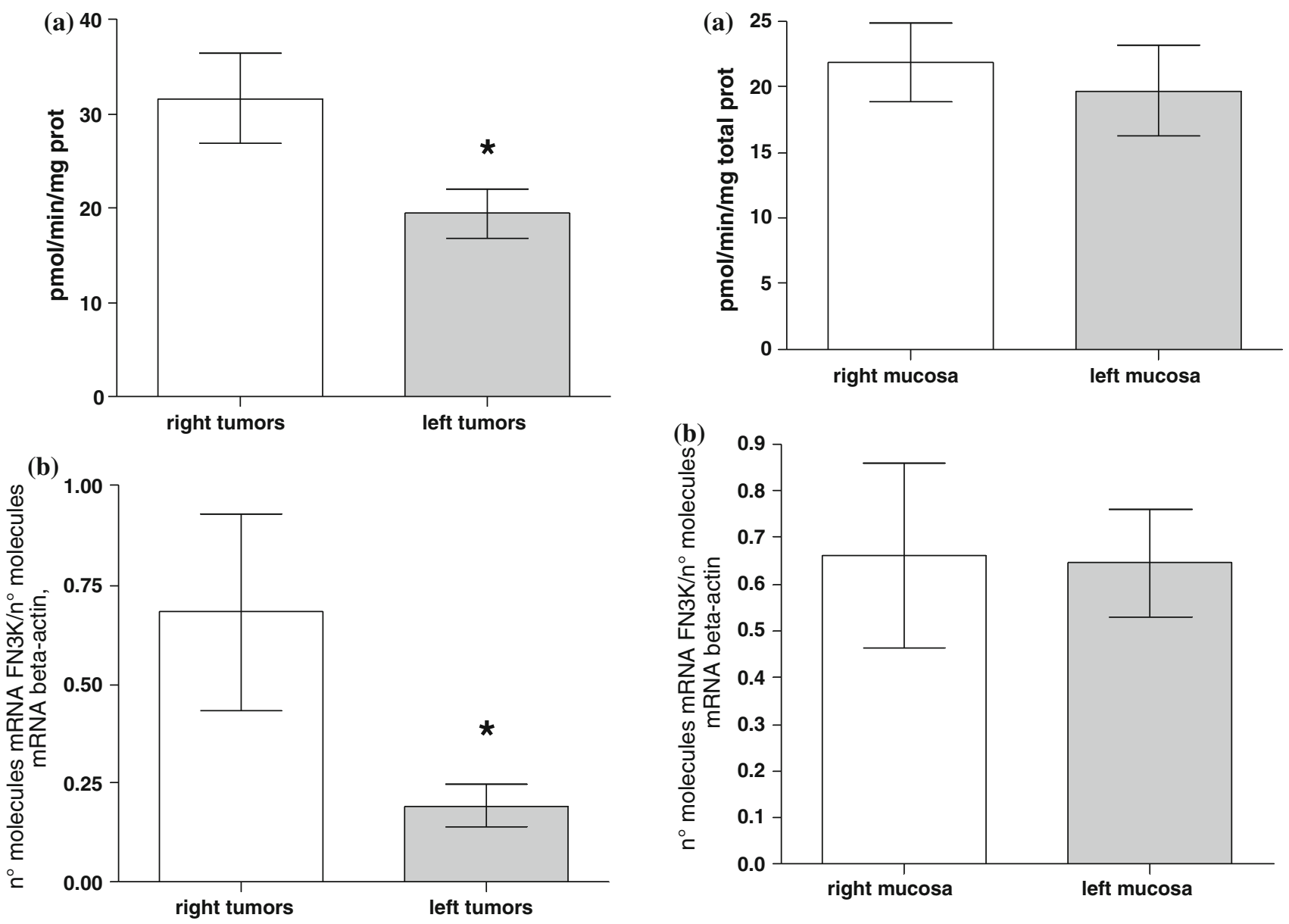

Fig. 2 Differences in FN3K activity (a) and mRNA (b) levels between right- and left-sided CRC (31.6 \pm 4.8 vs. $19.4 \pm 2.5$ pmol $\min ^{-1} \mathrm{mg}^{-1}$ protein, mean values $\pm \mathrm{SE}, * P=0.02$, unpaired $t$ test and $0.68 \pm 0.24$ vs. $0.19 \pm 0.05$ mean values $\pm S E$, expressed as $n^{\circ}$ molecules mRNA FN3K/n ${ }^{\circ}$ molecules mRNA $\beta$-actin, ${ }^{*} P=0.007$, unpaired $t$ test, respectively)

unpaired $t$ test; Fig. 2a, b, respectively). There are no significant differences in FN3K enzymatic activity and its mRNA in normal surrounding mucosa between left and right colon side (Fig. 3a, b, respectively).

No difference was detected in FN3K activity and mRNA levels according to clinico-histopathologic features of patients.

\section{Discussion}

This paper is the first studying FN3K enzyme activity in human colorectal cancer, showing a significant relationship between enzymatic activity, its mRNA and tumor side.

The tumors located at left side showed a reduced FN3K activity and mRNA gene expression respect to the tumors located at right side. The differences, in FN3K activity and mRNA, between proximal and distal colon tumor underline

Fig. 3 Differences in FN3K activity (a) and mRNA (b) levels in normal surrounding mucosa between right and left colon side $\left(21.8 \pm 2.9\right.$ vs. $19.7 \pm 3.4 \mathrm{pmol} \mathrm{min}^{-1} \mathrm{mg}^{-1}$ protein, mean values $\pm \mathrm{SE}, P>0.05$, unpaired $t$ test and $0.66 \pm 0.19$ vs. $0.64 \pm 0.11$ mean values $\pm \mathrm{SE}$, expressed as $\mathrm{n}^{\circ}$ molecules mRNA FN $3 \mathrm{~K} / \mathrm{n}^{\circ}$ molecules mRNA $\beta$-actin, $P>0.05$, unpaired $t$ test, respectively)

the biochemical regional variability of colon neoplastic transformation. A biological difference between proximal and distal colon tumors has been observed also for other enzymes, growth factors and multiple genetic alterations $[7,13,14,18]$. We have previously already observed that different biochemical pathways linking proliferation and tumor progression are modified in a different manner in the large bowel, suggesting a different susceptibility of colon regions to neoplastic transformation [7, 18].

On the right side of colon, the tumors have higher levels of FN3K activity and gene expression respect to the tumors located on the left side. This enzyme seems catalyze a repair mechanism offering selective cell advantage. The end products of glycation reactions inflict molecular damage through cross-linking, conformational changes, binding of redox active metals, ecc [4]. For these reasons, it is important to rid proteins of their sugar adducts rather than replace them with newly synthesized macromolecules. Different studies have demonstrated a better clinical 
outcome for the patients with proximal colorectal cancer with respect to distal colorectal cancer [2, 11]. Colonic cells of proximal colon appear to have more efficient mechanisms to protect their proteins against the glycating effects of high glucose or fructose compared to distal colon cells. Likely, due to the down-regulation of FN3K enzyme and its mRNA, an accumulation of AGEs could be present in tumors located in the left side with disregulation of the control cell growth.

There is growing body of evidences to show that AGEs and their receptor (RAGE) interactions are involved in the development of human CRC [12, 21, 27]. It has recently been hypothesized that AGEs could explain the molecular link between diabetes and CRC [27]. Elevated glucose concentrations lead to an increase in oxidative stress, to the activation of protein kinase $\mathrm{C}$, to the formation of Amadori products and AGEs, all of which have been hypothesized to play a role in the malignant transformation of colorectal mucosa $[12,21]$. Colorectal cancer and diabetes are common diseases that share many risk factors. A comparison of the risk factors of proximal and distal colorectal cancer showed that type 2 diabetes is associated with distal colorectal cancer in men [19]. In contrast, another study has shown that the patients with poorly controlled type 2 diabetes had more right-sided CRCs [23].

Our data confirm that down-regulation of FN3K enzyme activity and its gene expression is a characteristic of the left-sided colon tumors.

Further studies will be necessary to address whether disregulation of this enzyme associated with biologic factors as tumor side plays a role in CRC development and patient outcome.

\section{References}

1. Baynes JW (1991) Role of oxidative stress in development of complications in diabetes. Diabetes 40:405-412

2. Bazan V, Migliavacca M, Zanna I, Tubiolo C, Corsale S, Calo V, Amato A, Cammareri P, Latteri F, Grassi N, Fulfaro F, Porcasi R, Morello V, Nuara RB, Dardanoni G, Salerno S, Valerio MR, Dusonchet L, Gerbino A, Gebbia N, Tomasino RM, Russo A (2002) DNA ploidy and S-phase fraction but not p53 or NM23-HI expression predictoutcome in colorectal cancer patients. Result of a 5-year prospective study. J Cancer Res Clin Oncol 128: 650-658

3. Brown T, Sut B, Brown KA, Schwartz MA, Tobia AM, Kappler F (2003) Modulation of in vivo 3-deoxyglucosone levels. Biochem Soc Trans 31:1433-1437

4. Brownlee M (1994) Glycation and diabetic complications. Diabetes 43:836-841

5. Brownlee M (2001) Biochemistry and molecular cell biology of diabetic complications. Nature 414:813-820

6. Caruso MG, Notarnicola M, Altomare DF, Misciagna G (2007) Gene expression of Fructosamine 3-Kinase in patients with colorectal cancer. Oncology 73:72-75
7. Caruso MG, Notarnicola M, Bifulco M, Laezza C, Guerra V, Altomare DF, Memeo V, Lorusso D, Demma I, Di Leo A (2003) Increased farnesyltransferase activity in human colorectal cancer: relationship with clinicopathological features and K-ras mutation. Scand J Gastroenterol 38:80-85

8. Delpierre G, Van Schaftigen E (2003) Fructosamine3-kinase, an enzyme involved in protein deglycation. Biochem Soc Trans 31:1354-1357

9. Delpierre G, Vertommen D, Communi D, Rider H, Van Schaftigen $\mathrm{E}$ (2004) Identification of fructosamine residues deglycated by fructosamine-3-kinase in human hemoglobin. J Biol Chem 279:27613-27620

10. Fortpied J, Maliekal P, Vertommen D, Van Schaftigen E (2006) Magnesium-dependent phosphatase-1 is a protein-fructosamine6-phosphatase potentially involved in glycation repair. J Biol Chem 281:18378-18385

11. Kapiteijn E, Liefers GJ, Los LC, Kranenbarg E, Hermans J, Tollenaar RAEM, Moriya Y, van de Velde CJH, van Krieken JHJM (2001) Mechanisms of oncogenesis in colon versus rectal cancer. J Pathol 195:171-178

12. Kuniyasu H, Chihara Y, Takahashi T (2003) Co-expression of receptor for advanced glycation and products and the ligand amphoterin associate closely with metastasis of colorectal cancer. Oncol Rep 10:445-448

13. Li F-y, Lai M (2009) Colorectal cancer, one entity or three. J Zhejiang Univ Sci B 10(3):219-229

14. Messa C, Russo A, Caruso MG, Di Leo A (1998) EGF, TGF- $\alpha$ and EGF-R in human colorectal adenocarcinoma. Acta Oncol 37:285-289

15. Misciagna G, De Michele G, Guerra V, Cisternino AM, Di Leo A, Freudenheim JL, INTEROSP Group (2004) Serum fructosamine and colorectal adenomas. Eur J Epidemiol 19:425-432

16. Monnier VM (2005) Bacterial enzymes that can deglycate glucose-and fructose-modified lysine. Biochem J 392:e11-e13

17. Monnier VM (2006) The fructosamine 3 Kinase knockout mouse: a tool for testing the glycation hypothesis of intracellular protein damage in diabetes and aging. Biochem J 399:e11-e13

18. Notarnicola M, Messa C, Pricci M, Guerra V, Altomare D, Montemurro S, Caruso MG (2004) Up-regulation of 3-hydroxy3-methylglutaryl coenzyme a reductase activity in left sided human colon cancer. Anticancer Res 24:3837-3842

19. Oh SW, Kim YH, Choi YS, Chang DK, Son HJ, Rhee PL, Kim JJ, Rhee JC, Yun SH, Lee WY, Chun HK, Kim DH, Shim SG (2008) The comparison of the risk factors and clinical manifestations of proximal and distal colorectal cancer. Dis Colon Rectum 51(1):56-61

20. Peppa M, Raptis SA (2008) Advanced glycation end products and cardiovascular disease. Curr Diab Rev 4(2):92-100

21. Sasahira T, Akama Y, Fujii K, Kuniyasu H (2005) Expression of receptor for advanced glycation end products and HMGB1/ amphoterin in colorectal adenomas. Virchow Archiv 446: 411-415

22. Shinohara M, Thornalley PJ, Giardino I, Beisswenger P, Thorpe S, Onorato J, Brownlee M (1998) Overexpression of glyoxalase I in bovine endothelial cells inhibits intracellular advanced glycation endproduct formation and prevents hyperglycemia-induced increases in macromolecular endocytosis. J Clin Invest 101:1142-1147

23. Siddiqui A, Spechler SJ, Huerta S, Dredar S, Little BB, Cryer B (2008) Elevated HbAlc is an independent predictor of aggressive clinical behaviour in patients with colorectal cancer: a casecontrol study. Dig Dis Sci 53(9):2486-2494

24. Smit A, Lutgers H (2004) The clinical relevance of advanced glycation endproducts (AGE) and recent developments in pharmaceutics to reduce AGE accumulation. Curr Med Chem $11: 2767-2784$ 
25. Szwergold BS, Howell S, Beisswenger PJ (2001) Human fructosamine-3-kinase: purification, sequencing, substrate specificity and evidence of activity in vivo. Diabetes 50:2139-2147

26. Van Schaftigen E, Delpierre G, Collard F, Fortpied J, Gemayel R, Wiame E, Veiga-da-Cunha M (2007) Fructosamine 3 kinase and other enzymes involved in protein deglycation. Adv Enzyme Regul 47:261-269
27. Yamagishi S, Nakamura K, Inoue H, Kikuchi S, Takeuchi M (2005) Possible participation of advanced glycation end products in the pathogenesis of colorectal cancer in diabetic patients. Med Hypotheses 64:1208-1210

28. Yamagishi S, Ueda S, Okuda S (2007) Food-derived advanced glycation end products (AGEs): a novel therapeutic target for various disorders. Curr Pharm Des 13(27):2832-2836 